\title{
Correlation Between Salivary, Platelet and Central Serotonin Levels in Children
}

\author{
Csilla Egri(10, Mary Dunbar, Gabriella Ana Horvath (10
}

\begin{abstract}
Background: Serotonin (5-HT) is a neurotransmitter synthesized in both the central nervous system (CNS) and in enterochromaffin cells of the gut. 5-HT biosynthesis is separate between the periphery and the CNS. Any observed correlations between centrally and peripherally measured 5-HT remain to be elucidated. Previous efforts have looked for a noninvasive marker of central serotonin, including serotonin in whole blood, plasma, platelets, saliva, and urine; however, results are conflicting. Aim: Finding a noninvasive marker for central serotonin turnover that can be used for diagnosis and therapeutic monitoring in patients with primary neurotransmitter deficiencies. Methods: Inclusion criterion was all children presenting with neurological symptoms whose clinical investigations included lumbar puncture (LP) for cerebrospinal fluid (CSF) collection and neurotransmitter metabolite analysis, were recruited. For central serotonin turnover, the serotonin metabolite 5-hydroxyindoleacetic acid (5HIAA) was used. Bivariate correlation between the serotonin levels in CSF (5HIAA), platelets, and saliva was calculated. Results: Twenty-six patients (aged 6 months to 15 years) with various neurologic presentations had LP for CSF collection and neurotransmitter metabolite analysis as part of their clinical care. An additional salivary and blood sample was obtained at the same time. Eighteen patients had suitable samples for quantitative measure of serotonin. There was no correlation between platelet serotonin and CSF 5HIAA levels (Pearson's coefficient of correlation - PCC: 0.010) or between salivary serotonin and CSF 5HIAA (PCC: 0.258). There was a strong negative correlation between salivary and platelet serotonin (PCC: -0.679). Conclusion: Our findings suggest that salivary serotonin measurement is not a suitable noninvasive marker for measuring central serotonin turnover.
\end{abstract}

RÉSUMÉ : Corrélation entre les niveaux de sérotonine de la salive, des plaquettes et du liquide céphalo-rachidien chez les enfants. Contexte : La sérotonine (5-HT) est un neurotransmetteur synthétisé à la fois dans le système nerveux central (SNC) et dans les cellules entérochromaffines des intestins. Cela dit, la biosynthèse de la 5-HT demeure séparée entre sa périphérie et le SNC; de plus, toute corrélation observée entre les niveaux de 5-HT du SNC et des intestins reste à élucider. Des travaux de recherche précédents ont cherché à déterminer un marqueur non invasif de la 5-HT du SNC, ce qui inclut la 5-HT que l'on trouve dans le sang total (whole blood), le plasma, les plaquettes, la salive et l'urine. Il n'empêche que les résultats demeurent encore contradictoires. Objectif: Trouver un marqueur non invasif du renouvellement (turnover) de la 5-HT du SNC qui pourrait être utilisé pour le diagnostic et le suivi thérapeutique de patients atteints de déficiences des principaux neurotransmetteurs. Méthodes : Ont été inclus dans cette étude tous les enfants donnant à voir des symptômes neurologiques révélés par des examens cliniques ayant inclus des ponctions lombaires visant à recueillir de la 5-HT au niveau du SNC et une analyse des métabolites de leurs neurotransmetteurs. Pour mesurer le renouvellement de la 5-HT du SNC, nous avons fait appel au métabolite 5HIAA. Enfin, nous avons calculé la corrélation bi-variée entre les niveaux de 5-HT du SNC (5HIAA), des plaquettes et de la salive. Résultats : Au total, 26 patients âgés de 6 mois à 15 ans et donnant à voir diverses affections neurologiques ont fait l'objet, dans le cadre des soins cliniques leur étant prodigués, de ponctions lombaires et d'analyses des métabolites. Des échantillons additionnels de salive et de sang ont également été obtenus en même temps. Sur ces 26 patients, 18 ont procuré des échantillons convenant à une mesure quantitative de la 5-HT. Aucune corrélation n'a pu être établie entre les niveaux de 5-HT des plaquettes et ceux du SNC (5HIAA) (coefficient de corrélation de Pearson-CCP : 0,010) ou entre les niveaux de 5-HT de la salive et ceux du SNC (5HIAA) (CCP : 0,258). Enfin, aucune corrélation négative marquée n'a émergé entre les niveaux de 5-HT de la salive et ceux des plaquettes (CCP : - 0,679). Conclusion : Nos résultats suggèrent donc que la mesure des niveaux de 5-HT de la salive ne constitue pas un marqueur non invasif approprié permettant de déterminer le renouvellement de la 5-HT du SNC.

Keywords: Central serotonin, Salivary serotonin, Platelet serotonin, 5-HT, 5HIAA

doi:10.1017/cjn.2019.334

Can J Neurol Sci. 2020; 47: 214-218

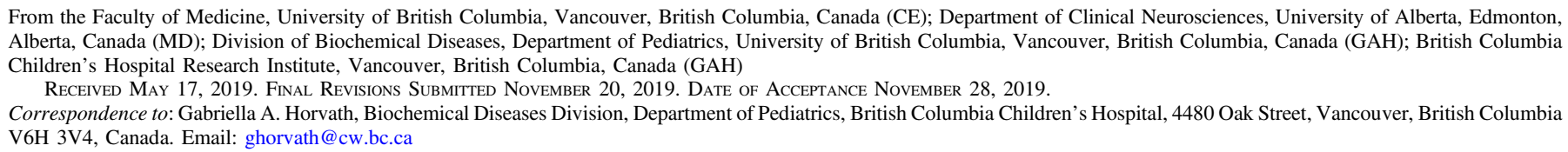




\section{BACKGROUND}

Serotonin (5-HT) is a monoamine neurotransmitter synthesized in both the central nervous system (CNS) and in the periphery. Serotonin is synthesized from the amino acid tryptophan by the enzyme tryptophan hydroxylase (TPH) and it is metabolized by the enzyme monoamine oxidase (MAO) into 5-hydroxyindoleacetic acid (5HIAA). In the CNS, serotonin is synthesized in the neurons of the midbrain raphe nuclei (centrally produced serotonin) and in the periphery in the enterochromaffin cells (ECCs) of the gut. The ECC produces almost $95 \%$ of the body's total serotonin, which overflows into the gastrointestinal lumen and blood. Very little free serotonin can be found in plasma, however, as platelets concentrate and store the vast majority of peripheral serotonin. $^{1,2}$

The rate-limiting step in serotonin synthesis is catalyzed by two genetically distinct isoforms of TPH. TPH2 is preferentially expressed in the brain, while TPHI is expressed peripherally and in the pineal gland, where serotonin serves as precursor for melatonin production. Thus, serotonin biosynthesis is spatially and biochemically segregated between the periphery and the CNS by the blood-brain barrier. ${ }^{3,4}$ The gold standard measurement of central serotonin is its metabolite, 5-HIAA in cerebrospinal fluid (CSF) via lumbar puncture (LP). ${ }^{5}$

Serotonin is stored intracellularly in vesicles and granules and is released by exocytosis. Reuptake of neuronal serotonin across presynaptic plasma membrane is mediated by the serotonin transporter (SERT), a member of the SLC6 sodium-dependent solute transporter family (SLC6A4). ${ }^{6}$ SERT is highly expressed in platelets that do not synthesize serotonin, but store serotonin produced by the ECC.

Serotonin plays a diverse role in the regulation of cardiovascular function, breathing, circadian rhythms, sleep, appetite, mood, and learning. ${ }^{1}$ It influences a wide range of psychiatric disorders, and serotonin has been targeted for many pharmacologic approaches to managing depression and anxiety. ${ }^{7}$ Serotonin and its numerous receptor subtypes are involved with behavioral and neuroendocrine processes that provide life-preserving responses to stress. Serotonin plays an important role in vascular resistance and blood pressure control, and a functional SERT polymorphism has been associated with migraine. ${ }^{8}$ Serotonin also has been the topic for research in neurodegenerative disorders, spinal cord injury, and sudden unexpected death in epilepsy. ${ }^{9-11}$ In addition, prior to assuming its role as a neurotransmitter, serotonin acts as a trophic signal in the developing brain by directing neural ontogeny of the 5-HT and other neurochemical systems. As a developmental signal, serotonin regulates cell migration, axonal outgrowth, and synaptogenesis, and is a coordinating mediator of intracellular communication. It is therefore conceivable that changing levels of serotonin during prenatal development may alter subsequent structure and function of the serotonergic system. ${ }^{12}$

The aim of the current study was to find an easy, noninvasive peripheral biomarker that correlates with central serotonin turnover. The clinical significance of this aim would be to avoid invasive LPs for diagnosis and therapeutic monitoring of patients with primary neurotransmitter deficiencies, such as biopterin defects, for example, GTP cyclohydrolase deficiency, 6-pyruvoyltetrahydropterin synthase deficiency, and sepiapterin reductase deficiency. ${ }^{13}$ Patients with primary neurotransmitter deficiencies are diagnosed by measuring CSF serotonin and dopamine metabolites, but most importantly need serial LPs to monitor the effects of treatment, such as serotonin replacement therapy with 5-Hydroxytryptophan.

\section{Methods}

University Research Ethics Board approval was obtained for enrolling patients and performing the study (IRB\#H14-01822). All children between 6 months and 17 years, evaluated in Pediatric Neurology and Biochemical Genetics clinics, for a variety of neurological presentations, including developmental delay and seizures were recruited in a nonconsecutive manner. Only children whose routine clinical care included an LP for CSF collection and neurotransmitter metabolite analysis were included. An additional salivary and blood sample was obtained at the time of LP. Only patients whose LP was unsuccessful were excluded. No LP was performed on children for the sole purpose of this study.

LP was performed in a fasted state, in the morning. Fractions were collected in separate tubes according to protocol, immediately frozen and analyzed according to established methods in a clinical laboratory using previously reported methods. ${ }^{13,14}$

Blood sample was collected in Na citrate tubes, then submitted to a soft spin at $140 \mathrm{~g} \times 10$ minutes. The supernatant was removed to obtain platelet-rich plasma and frozen at $-80^{\circ} \mathrm{C}$ until further analysis. All experiments were conducted in clear plastic tubes and at room temperature. Approximately $0.2-0.5 \mathrm{ml}$ saliva samples were collected using a clean pipette from the mouth, frozen immediately and kept in $-80^{\circ} \mathrm{C}$ until further analysis. Platelet and salivary serotonin were measured using a highly sensitive Enzyme Immunoassay kit (DLD Diagnostika GMBH, Catalog\# 630/96).

Analysis: Pearson's coefficient of correlation (PCC) was calculated for pairwise comparisons of saliva, plasma, and CSF serotonin. Significance was set at $\alpha=0.05$, using a two-tailed test.

\section{Results}

Twenty-six patients were recruited, of whom 18 had suitable samples and were included for analysis. The age of patients ranged from 6 months to 15 years with an average age of 9.1 years (standard deviation 4.9), and were 57\% male (Table 1).

Twelve patients had CSF 5HIAA level in the normal range for their age. Five patients had values below normal, and one patient had a supranormal value (Table 1).

There was no correlation between platelet serotonin and CSF 5HIAA levels (PCC:0.010, $p=0.969$ ) or between salivary serotonin and CSF 5HIAA (PCC: $0.258, p=0.318$ ). There was a strong negative correlation between salivary and platelet serotonin (PCC: $-0.679, p=0.002$ ) (Figure 1).

\section{Discussion}

We know the source of serotonin in the brain and in blood. There is no clear data on the origins of salivary serotonin, although we know that many of the catecholamines and hormones are readily detectable in saliva, but other than steroid hormone levels, their quantification doesn't correlate very well with plasma levels. Most steroids can cross readily the 


\section{Table 1: Results of platelet, saliva serotonin, and CSF 5HIAA levels}

\begin{tabular}{|c|c|c|c|c|c|c|}
\hline \multirow{2}{*}{ Sample } & \multirow{2}{*}{$\begin{array}{c}\text { Age } \\
\text { (years) }\end{array}$} & \multirow{2}{*}{ Sex } & \multirow{2}{*}{$\begin{array}{c}\begin{array}{c}\text { Platelet-rich } \\
\text { plasma } \\
\text { serotonin } \\
(\mathbf{n g} / \mathbf{m l})\end{array} \\
\mathbf{n g} / \mathbf{m l}\end{array}$} & \multirow{2}{*}{$\begin{array}{c}\begin{array}{c}\text { Salivary } \\
\text { serotonin } \\
(\mathbf{n g} / \mathrm{ml})\end{array} \\
\mathrm{ng} / \mathrm{ml}\end{array}$} & \multicolumn{2}{|c|}{ CSF 5HIAA } \\
\hline & & & & & $\mathrm{nmol} / \mathrm{L}$ & $\mathrm{ng} / \mathrm{m}$ \\
\hline 01 & 6 & M & 1529.6 & 12.216 & 105 & 18.5 \\
\hline 02 & 6 & F & 1274.4 & 8.846 & 62 & 10.9 \\
\hline 03 & 6 & $\mathrm{~F}$ & 79 & 676.977 & 170 & 29.9 \\
\hline 04 & 9 & M & - & 599.615 & - & - \\
\hline 05 & 1.5 & F & 1340.5 & 12.67 & 132 & 23.2 \\
\hline 06 & 11 & M & 1170.8 & 38.187 & 138 & 24.3 \\
\hline 07 & 13 & F & - & 3.315 & - & - \\
\hline 08 & 10 & M & 1257.8 & 11.341 & 279 & 49.1 \\
\hline 09 & 15 & F & 164.5 & 4.73 & 47 & 8.2 \\
\hline 10 & 2 & M & - & - & - & - \\
\hline 11 & 0.5 & M & - & 115.058 & - & - \\
\hline 12 & 10 & M & 274.6 & 118.526 & 118 & 20.8 \\
\hline 13 & 15 & F & 1889.5 & 32.568 & 113 & 19.9 \\
\hline 14 & 1.5 & F & 1458.7 & 43.595 & 121 & 21.3 \\
\hline 15 & 9 & M & 999.9 & 56.228 & 121 & 21.3 \\
\hline 16 & 11 & M & 32.5 & 513.375 & 194 & 34.2 \\
\hline 17 & 14 & F & 70.8 & 298.076 & 73 & 12.8 \\
\hline 18 & 11 & M & - & 43.051 & - & - \\
\hline 19 & 11 & F & 1641.2 & 17.021 & 106 & 18.7 \\
\hline 20 & 15 & F & 196.7 & 160.491 & 31 & 5.5 \\
\hline 21 & 14 & M & 1294 & 71.579 & - & - \\
\hline 22 & 10 & M & 1203.3 & - & 114 & 20.1 \\
\hline 23 & 7 & M & 959.9 & 43.738 & 128 & 22.5 \\
\hline 24 & 15 & $\mathrm{~F}$ & 1640.7 & 49.024 & 29 & 5.1 \\
\hline 25 & 0.5 & M & - & 58.32 & - & - \\
\hline 26 & 15 & M & - & 42.336 & - & - \\
\hline
\end{tabular}

Reference ranges for CSF 5HIAA age related: $6-9$ years: $66-338 \mathrm{nmol} / \mathrm{L}$; 10-14 years: $67-189 \mathrm{nmol} / \mathrm{L}$; 15 years: $67-140 \mathrm{nmol} / \mathrm{L}$.

phospholipid membrane of epithelial cells lining the blood vessels by simple diffusion, but this has not been proven for serotonin. ${ }^{15}$ Serotonin has opposing effect on salivary glands and on secretion of saliva. Serotonin treatment decreases salivary flow rate and protein content. This is a receptor-mediated action of 5-HT, by increasing intracellular cAMP accumulation. ${ }^{16}$ This is the most likely explanation for the negative correlation between platelet and salivary serotonin. Increase in blood serotonin will decrease salivary flow rate and protein content.

Saliva is a clinically informative biofluid that is used for novel approaches for diagnosis, monitoring, and management of patients with systemic disease. ${ }^{17}$ Such salivary biomarkers are cortisol, nitrite, uric acid, sodium, chloride, $\mathrm{pH}$, amylase, and lactoferrin used in end-stage renal disease; cancer antigens in malignancies; and specific antibody reactivity to pathogens in infectious diseases. ${ }^{17}$ It is easily collected and stored and would be ideal for use as a peripheral biomarker.

Although we don't know the exact mechanism by which serotonin enters the oral cavity, it appears that it is mostly influenced by the blood serotonin levels and doesn't appear to be a good peripheral biomarker for central serotonin turnover (Figure 2).

Previous experiments have sought a noninvasive surrogate marker of central serotonin, including serotonin in whole blood, plasma, platelets, saliva, and urine. An alternative, noninvasive method of neurotransmitter assessment could eliminate the need for painful and resource-intensive LP and increase the possibility of quick, routine testing and monitoring of central serotonin levels. ${ }^{18-21}$ Differences in study design, however, yield conflicting results. The mechanism responsible for any observed correlations between centrally and peripherally measured serotonin remains to be elucidated.

CSF 5HIAA has been used in this study instead of CSF 5-HT (serotonin) as it has been shown to reflect central serotonin turnover. ${ }^{5}$ The distribution of 5-HT and its metabolite 5HIAA was similar and correlating in a study comparing ventricular CSF monoamine transmitter and metabolite concentrations in 14 autopsy cases. ${ }^{5}$ It is used as a standard measurement for diagnosing all primary neurotransmitter disorders. ${ }^{13}$ On the other hand, plasma and salivary 5HIAA levels are more variable and highly fluctuating in response to high dietary intake of biogenic amine foods (bananas, pineapple, plantain, and kiwi), in contrast with platelet serotonin which does not show significant change. ${ }^{22}$

There have been conflicting reports comparing CSF serotonin with plasma or platelet serotonin, and our study corroborates that there is no correlation among these measures. We have measured CSF 5HIAA, as marker for central serotonin turnover, which closely correlates with CSF 5-HT. We think that this did not influence the results of the study. One of the limitations of the study is that the cohort was too small for meaningful statistical analysis. However, when we plotted the data (figure not shown), the correlation made sense.

Some of the pitfalls in previously reported 5-HT measurements that may have not been accounted for and some of our precautions to mitigate for these pitfalls were:

1. A diet rich in tryptophan (bananas, chocolate, pineapples, plums, and nuts) will increase the levels of plasma and to lesser degree that of platelet serotonin. We collected all samples after a 12-hour overnight fast, to avoid even the small influence of diet on platelet serotonin.

2. Time of the day for collection is important, as 5-HT levels are highest in the morning in plasma. We collected all samples between 9 and $11 \mathrm{AM}$.

3. Certain medications (i.e. SSRIs, MAO inhibitors) will increase central serotonin levels. ${ }^{23}$ None of our patients were taking these medications.

4. Technical challenges (using glassware will cause platelets to stick to the wall). We used plastic tubes for centrifuge and storage of samples.

5. Plasma has very low levels of 5-HT, and platelets are difficult to isolate and work with. We have developed a platelet isolation method previously used in SERT activity measurement. ${ }^{24}$ 

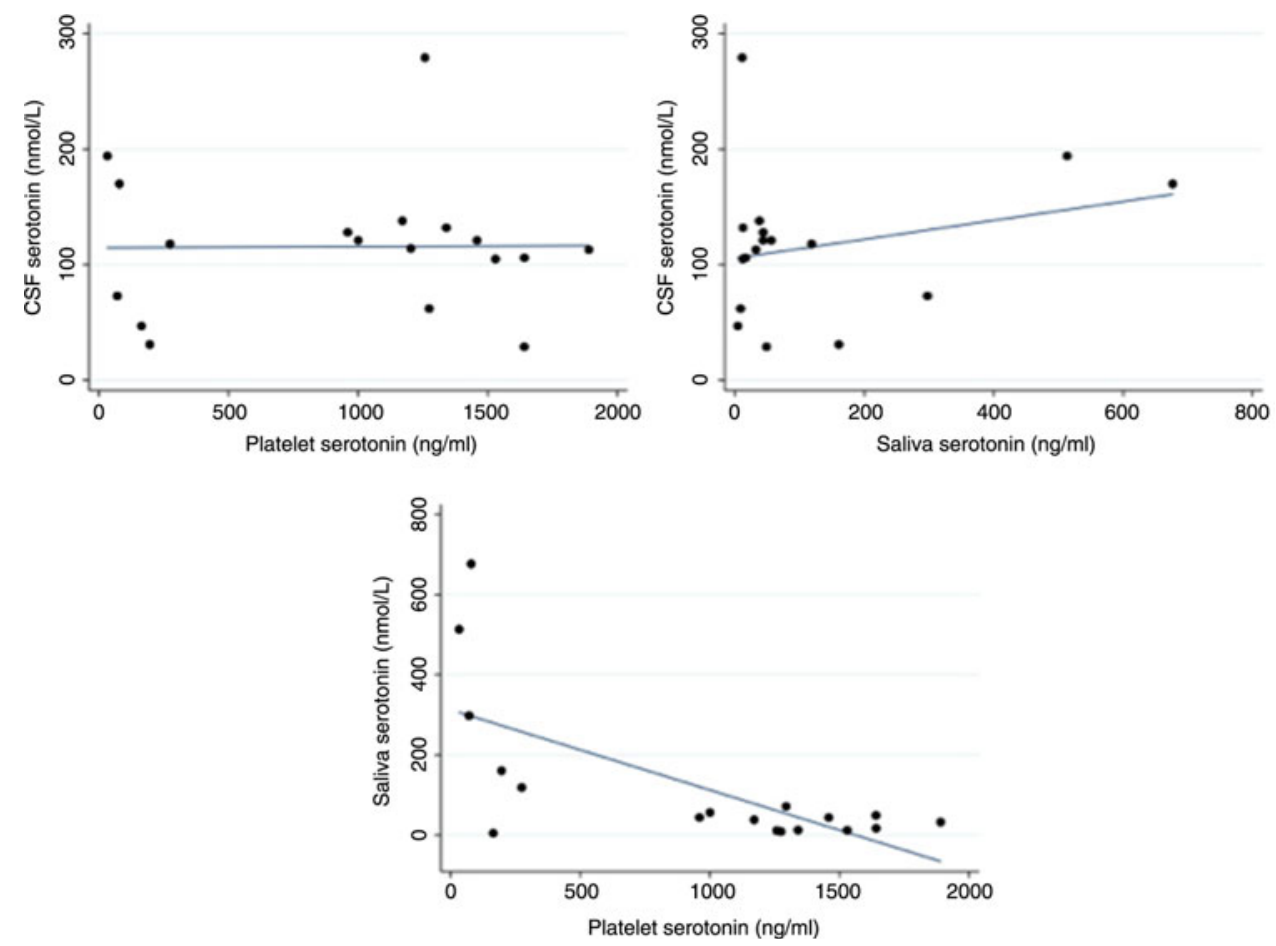

Figure 1: Scatter plots of CSF, saliva, and serum serotonin. Regression line of fitted values. (A) CSF serotonin vs. platelet serotonin, $P C C=0.01, p=0.97$. (B) CSF serotonin vs. saliva serotonin, $P C C=0.258, p=0.32$. (C) Saliva vs. platelet serotonin, $P C C=-0.68, p=0.002$.

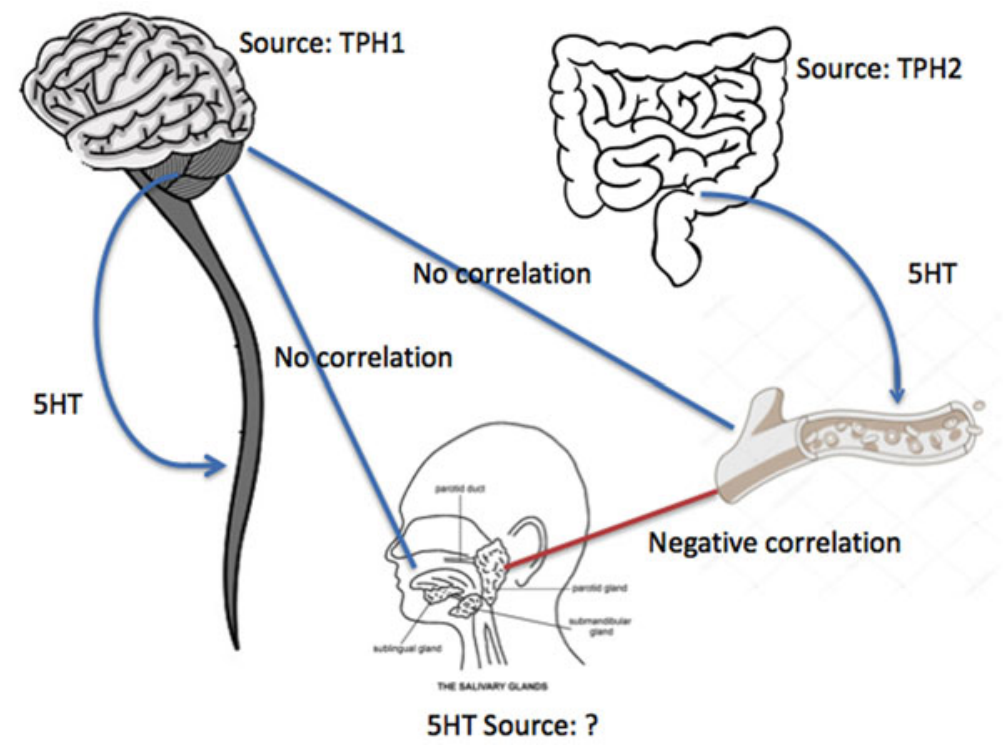

Figure 2: Illustration of sources of central and peripheral serotonin and their correlation.

6. CSF 5HIAA level has a gradient, and collection of the sample has to be performed according to a strict protocol (i.e. collection of the first $0.5 \mathrm{ml}$ of CSF after the first drop). We used the strict CSF sample collection protocol from the Hyland Lab.

\section{Conclusions}

We found no correlation between platelet serotonin and CSF 5HIAA levels or between salivary serotonin and CSF 5HIAA, suggesting that salivary serotonin should not be used as peripheral biomarker for central serotonin turnover in the setting of a 
Pediatric Neurology or Metabolic clinics for diagnosis or monitoring of treatment of patients with primary neurotransmitter deficiencies.

\section{ACKNOWLEDGMENTS}

We are grateful to the patients and families for their participation in the study, our medical colleagues from the Divisions of Pediatric Neurology and Biochemical Genetics for their management and referral, our Research Assistant Ms. Delia Apatean for recruiting patients and collecting saliva samples and Ms. Grace Yang for performing the Enzyme Immunoassay experiments in the lab.

\section{FUNDING}

This work was supported by the Rare Diseases Foundation grant \#F14-02307

\section{CONFLict OF INTEREST}

The authors have no conflicting interests to declare.

\section{Statement of Authorship}

GAH worked on conception and design, acquisition of data and drafted the manuscript; CE worked on conception and design, acquisition and analysis of the data and edited a significant portion of the manuscript; MD worked on acquisition and analysis of the data and edited a significant portion of the manuscript.

\section{REFERENCES}

1. Berger M, Gray JA, Roth BL. The expanded biology of serotonin. Ann Rev Med. 2009;60:355-66.

2. Muck-Seler D, Pivac N. Serotonin. Period Biol. 2011;113:29-41.

3. Walther DJ, Jens-Uve P, Saleh B, et al. Synthesis of serotonin by a second Tryptophan Hydroxylase isoform. Science Brevia. 2003;299:76.

4. Zhang X, Beaulieu JM, Sotnikova TD, et al. Tryptophan hydroxylase-2 controls brain serotonin. Science Brevia. 2004;305:217.

5. Wester P, Bergstrom U, Eriksson A, et al. Ventricular cerebrospinal fluid monoamine transmitter and metabolite concentrations reflect human brain neurochemistry in autopsy cases. J Neurochem. 1990;54:1148-56.
6. Blakely RD, DeFelice LJ, Galli A. Biogenic amine neurotransmitter transporters: just when you thought you knew them. Physiology. 2005;20:225-31.

7. Baldwin D, Rudge S. The role of serotonin in depression and anxiety. Int Clin Psychopharmacol. 1995;9:S41-45.

8. Schurks M, Rist PM, Kurth T. 5-HTTLPR polymorphism in the serotonin transporter gene and migraine: a systematic review and meta-analysis. Cephalalgia. 2010;30:1296-1305.

9. Azmitia EC, Nixon R. Dystrophic serotonergic axons in neurodegenerative diseases. Brain Res. 2008;1217:185-94.

10. Murray K, Nakae A, Stephens M, et al. Recovery of motoneuron and locomotor function after spinal cord injury depends on constitutive activity in 5-HT2c receptors. Nat Med. 2010;16:694-700.

11. Richerson G. Serotonin: the anti-sudden death amine? Epilepsy Curr. 2013;13:241-44.

12. Gaspar P, Cases O, Maroteaux L. The developmental role of serotonin: news from mouse molecular genetics. Nat Rev Neurosci. 2003;4:1002-12.

13. Hyland $\mathrm{K}$. The lumbar puncture for diagnosis of pediatric neurotransmitter diseases. Ann Neurol. 2003;54:S13-17.

14. Hyland K, Surtees RA, Heales SJ, et al. Cerebrospinal fluid concentrations of pterins and metabolites of serotonin and dopamine in a pediatric reference population. Pediatr Res. 1993;34:10-14.

15. Kennedy B, Dillon E, Mills PJ, Ziegler MG. Catecholamines in human saliva. Life Sci. 2001;69:87-99.

16. Vaibhav PP, Marshall AM. Intraluminal homeostasis. A common serotonergic mechanism among diverse epithelia. Comm Integ Biol. 2011;4:532-37.

17. Malamud D, Rodriguez-Chavez IR. Saliva as a diagnostic fluid. Dent Clin North Am. 2011;55:159-78.

18. Sarrias MJ, Cabre P, Martinez E, Artigas F. Relationship between serotonergic measures in blood and cerebrospinal fluid simultaneously obtained in humans. J Neurochem. 1990;54:783-86.

19. Pietraszek MH, Takada Y, Yan D, et al. Relationship between serotonergic measures in periphery and the brain of mouse. Life Sci. 1992;51:75-82.

20. Yan D, Urano T, Pietraszek MH, et al. Correlation between serotonergic measures in cerebrospinal fluid and blood of subhuman primate. Life Sci. 1992;52:745-49.

21. Audhya T, Adams JB, Johansen L. Correlation of serotonin levels in CSF, platelets, plasma and urine. Biochim Biophys Acta. 2012;1820:1496-501.

22. Kema IP, Schellings AMJ, Meiborg G, et al. Influence of a serotoninand dopamine-rich diet on platelet serotonin content and urinary excretion of biogenic amines and their metabolites. Clin Chem. 1992;38:1730-36.

23. Anderson GM. Peripheral and central neurochemical effects of the selective serotonin reuptake inhibitors (SSRIs) in humans and nonhuman primates: assessing bioeffect and mechanism of action. Int J Devl Neurosci. 2004;22:397-404.

24. Horvath GA, Selby K, Poskitt K, et al. Hemiplegic migraine, seizures, progressive spastic paraparesis, mood disorder and coma in siblings with low systemic serotonin. Cephalalgia. 2011;31:1580-86. 